\title{
A Case of Obstructive Colitis with Elevated Serum Carcinoembryonic Antigen
}

Hitoshi Kameyama*, Masayuki Nagahashi, Yuki Hirose, Natsuru Sudo, Yosuke Tajima, Masato Nakano, Yoshifumi Shimada, Takashi Kobayashi, Shin-ichi Kosugi and Toshifumi Wakai

Niigata University, Niigata city, Japan

\begin{abstract}
We report the case of a 72-year-old female who was admitted to our hospital because of obstructive colitis. Blood analysis showed her serum carcinoembryonic antigen (CEA) level to be $156.0 \mathrm{ng} / \mathrm{mL}$. A sigmoidectomy and descending colostomy were performed for obstructive colitis due to colonic diverticulitis. Histopathological examination revealed active inflammation of the sigmoid colon without neoplasia. Her serum CEA level decreased within normal limits immediately after surgery.
\end{abstract}

Keywords: Carcinoembryonic antigen (CEA); Obstructive colitis; Diverticulitis; Colectomy

\section{Introduction}

The cell surface glycoprotein Carcinoembryonic Antigen (CEA) is commonly used as a tumor marker for various malignancies [1]. However, serum CEA levels sometimes increase secondary to benign diseases or conditions, including inflammatory bowel disease (IBD), liver disease, pancreatitis, and smoking [2]. Therefore, differential diagnosis with high serum CEA levels includes both benign and malignant disease.

\section{Case Presentation}

A 72-year-old female was admitted to our hospital because of abdominal pain. The physical examination showed a distended tympanic abdomen and tenderness in the left abdominal quadrant. Her medical history included hypertension and Alzheimer's disease. She was $149.0 \mathrm{~cm}$ in height, weighed $42.8 \mathrm{~kg}$, and did not smoke cigarettes. Her body temperature was $37.8^{\circ} \mathrm{C}$, blood pressure was $160 / 80 \mathrm{mmHg}$, and pulse was $110 \mathrm{bpm}$ with regular rhythm. Blood analysis showed a white blood cell count of 7,470 cells $/ \mathrm{mm} 3$ and C-reactive protein level of 34.1 $\mathrm{mg} / \mathrm{dL}$. The level of her serum hemoglobin was $10.7 \mathrm{~g} / \mathrm{dL}$, blood urea nitrogen was $36.0 \mathrm{mg} / \mathrm{dL}$, and creatinine was $1.1 \mathrm{mg} / \mathrm{dL}$. Her serum CEA level was $156.0 \mathrm{ng} / \mathrm{mL}$ (normal value, $<5.0 \mathrm{ng} / \mathrm{mL}$ ). An abdominal $\mathrm{X}$-ray showed dilation of the large-bowel segment. An abdominopelvic Computed Tomography (CT) scan revealed a markedly dilated sigmoid colon with multiple colonic diverticula however, no malignant findings (Figure 1).

Obstructive colitis due to colonic diverticulitis was diagnosed

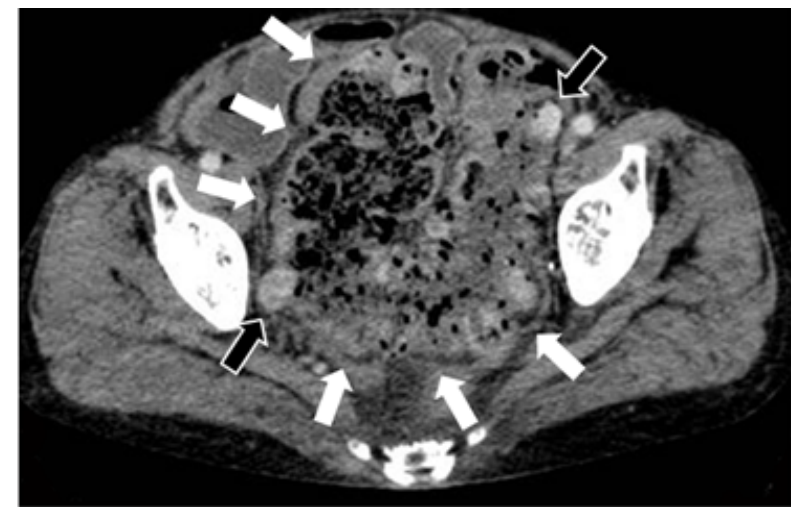

Figure 1: An abdominopelvic CT scan revealed a dilated sigmoid colon (white arrows) with multiple colonic diverticula (black arrows). and a sigmoidectomy and descending colostomy were performed. Histopathological examination revealed colonic diverticulitis without neoplasia. Her postoperative course was uneventful, and her serum CEA level decreased to within normal limits on postoperative day 18 . On postoperative day 19 , she was transferred to a psychiatric ward for the treatment of the Alzheimer's disease. Her serum CEA level has remained within normal limits since discharge.

\section{Case Discussion}

CEA was first detected by Gold et al in 1965 [3,4]. It is a highly glycosylated protein with a molecular weight of approximately 180,000 [1]. In healthy individuals, CEA is produced in the colorectal mucosa, and then released into the gut lumen where it disappears immediately. CEA is well-known as a tumor marker for various malignancies. In colorectal cancer, the neoplastic cells located deep inside tumor glands become unpolarized and express CEA on their entire cell surface. As a result, exfoliated CEA can enter blood and lymphatic vessels through the intercellular spaces [5].

Serum CEA levels also increase in benign diseases or conditions, including IBD, liver cirrhosis, hepatitis, pancreatitis, and smoking [2]. Gardner et al. reported that in patients with ulcerative colitis (UC), $24 \%$ of mild relapses and $86 \%$ of severe relapses were accompanied by elevated CEA titers [6]. In UC, serum CEA concentrations increase because of the up-regulation of colonic epithelial CEA expression secondary to active mucosal inflammation.

CEA expression is normally localized to the apical epithelial surface only in healthy subjects. However, during active UC, both the cytosolic and apical surfaces of the inflamed epithelial tissue stain positive for CEA [7]. In our case, immunohistochemistry showed CEA expression at both the cytosolic and apical surfaces of the inflamed epithelial tissue (Figure 2). Yamaguchi et al. [7] reported that in UC, CEA release from inflamed epithelia into the bloodstream could increase serum CEA

*Corresponding author: Hitoshi Kameyama, Niigata University, Niigata city, Japan, Tel: +81 25-223-6161; E-mail: kame@med.niigata-u.ac.jp

Received October 09, 2015; Accepted November 04, 2015; Published November 11,2015

Citation: Kameyama H, Nagahashi M, Hirose Y, Sudo N, Tajima Y, et al. (2015) A Case of Obstructive Colitis with Elevated Serum Carcinoembryonic Antigen. J Clin Case Rep 5: 635. doi:10.4172/2165-7920.1000635

Copyright: (c) 2015 Kameyama H, et al. This is an open-access article distributed under the terms of the Creative Commons Attribution License, which permits unrestricted use, distribution, and reproduction in any medium, provided the original author and source are credited. 

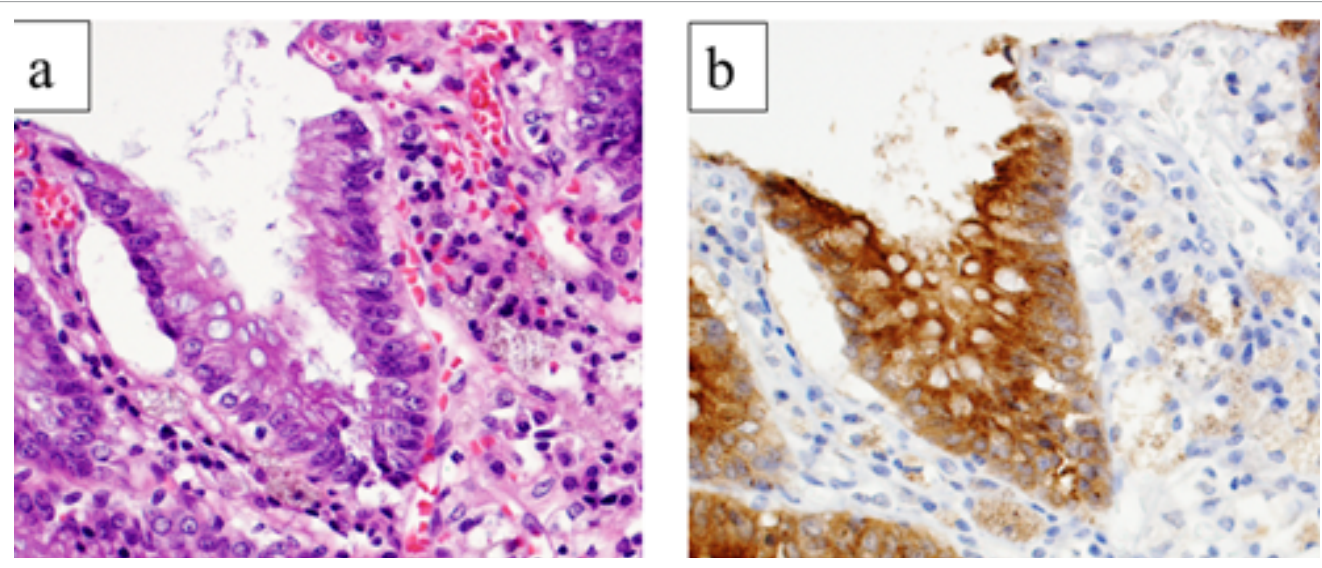

Figure 2 a: Microscopy (HE stain) showed inflamed colonic epithelia. b: Immunohistochemistry showed CEA expression at both the cytosolic and apical surface of colonic epithelia.

levels [7]. In our case, serum CEA levels decreased to within normal limits immediately after colectomy. We speculate that serum CEA elevation may have resulted from active colorectal inflammation.

\section{Conclusion}

We report the case of obstructive colitis with an elevated serum CEA concentration. CEA release from inflamed colonic epithelia into the bloodstream may have caused this increase. We must remember that elevated serum CEA levels are sometimes caused by benign colorectal disease involving active inflammation.

\section{References}

1. Benchimol S, Fuks A, Jothy S, Beauchemin N, Shirota K, et al. (1989) Carcinoembryonic antigen, a human tumor marker, functions as an intercellular adhesion molecule. Cell 57: 327-334.
2. Loewenstein MS, Zamcheck N (1978) Carcinoembryonic antigen (CEA) levels in benign gastrointestinal disease states. Cancer 42: 1412-1418.

3. Gold P, Freedman SO (1965) Demonstration of tumor-specific antigens in human colonic carcinoma by immunological tolerance and absorption techniques. J Exp Med 121: 439-462

4. Gold P, Freedman SO (1965) Specific carcinoembryonic antigens of the human digestive system. J Exp Med 122: 467-481.

5. Hammarström S (1999) The carcinoembryonic antigen (CEA) family: structures, suggested functions and expression in normal and malignant tissues. Semin Cancer Biol 9: 67-81.

6. Gardner RC, Feinerman AE, Kantrowitz PA, Gottblatt S, Loewenstein MS, et al. (1978) Serial carcinoembryonic antigen (CEA) blood levels in patients with ulcerative colitis. Am J Dig Dis 23: 129-133.

7. Yamaguchi S, Takeuchi Y, Arai K, Oishi C, Norose T, et al. (2012) Elevation of carcinoembryonic antigen coinciding with disease activity of ulcerative colitis. Clin J Gastroenterol 5: 150-154. 